\title{
Use of rapid carbohydrate utilisation test for identifying "Streptococcus milleri group"
}

\author{
J M Whitworth, P W Ross, I R Poxton
}

\begin{abstract}
A short series of biochemical and serological tests were developed for the rapid presumptive identification of "Streptococcus milleri group" isolates. One hundred and seventy seven streptococcal isolates were recovered from the mouths of 10 out of 12 healthy adult volunteers by use of a simple sampling procedure and a single selective medium. In all, 127 oral " $S$ milleri group" isolates were identified by biochemical and serological tests, confirming the indigenous nature of these streptococci in the mouth. Most $(70 \cdot 1 \%)$ of " $S$ milleri group" isolates were nonhaemolytic, $26 \%$ were $\alpha$-haemolytic, and $3.9 \% \beta$-haemolytic. Fifty four $(42.5 \%)$ were serologically typable, of which 46 were Lancefield group F, suggesting that the mouth is an important source of Lancefield group F streptococci. A collection of group $F$ streptococci from a range of sources was indistinguishable from a collection of oral " $S$ milleri group" isolates on the basis of the tests used, supporting the general synonymity of group $F$ streptococcus with the broader "S milleri group".
\end{abstract}

The battery of tests was cheap and simple to perform, and was capable of identifying " $S$ milleri group" isolates from a range of sources, including variants with wide sugar fermentation patterns.

The viridans streptococci have long been regarded as low grade pathogens contributing to the complex resident flora of a number of mucosal sites. Streptococci belonging to the "milleri group" are currently classified with the viridans streptococci, and are known to contribute to the resident flora of the gastrointestinal tract, ${ }^{1}$ the urogenital system, ${ }^{2}$ the upper respiratory tract, ${ }^{3}$ and the mouth, where a particular association with sheltered sites on hard surfaces has been shown. ${ }^{45}$ They are, however, unusual among the viridans streptococci in their association with deepseated sepsis in a range of sites, including surgical sepsis, ${ }^{6}$ hepatic abscesses, ${ }^{7}$ pleural empyema, ${ }^{8}$ intracranial sepsis ${ }^{9}$ and odontogenic abscesses. ${ }^{10}$ The mouth has often been regarded as the source of "Streptococcus milleri group" strains involved in abscess formation in many of these sites.

Despite its widespread use in the clinical setting, the title " $S$ milleri" has no official status in streptococcal taxonomy ${ }^{11}$ and is a title used to describe a collection of strains which have variously been referred to as Streptococcus anginosus, ${ }^{12}$ minute colony forming $\beta$ haemolytic streptococci, ${ }^{13}$ Streptococcus $M G,{ }^{14}$ Streptococcus milleri, ${ }^{15}{ }^{16}$ Streptococcus intermedius, ${ }^{1718}$ Streptococcus constellatus, ${ }^{17} 18$ Streptococcus anginosus-constellatus, ${ }^{19}$ and Streptococcus MG-intermedius. ${ }^{19}$ The "S milleri group", therefore, represents a complex aggregate of organisms which may display $\alpha, \beta$, or non-haemolysis on blood agar culture media, and may variably possess Lancefield group antigens $A, C, G$, or F. Heterogeneity in traditional biochemical tests has also been observed..$^{20}$ Recognised differences notwithstanding, these strains are currently classified within a single species, under the approved name $S$ anginosus. ${ }^{21}$ Taxonomic uncertainty persists, however, and recent studies have shown three distinct genotypes within the " $S$ milleri group" $" 22$; one homology group including the type strain of $S$ constellatus, one including the type strain of $S$ intermedius, and the final group including the type strain $S$ anginosus. A very recent report from the same authors has also described a biochemical scheme for the reliable phenotypic differentiation of these three genotypes, suggesting that they are incorrectly classified within a single species. ${ }^{23}$

The aims of the current study were: (i) to design a simple and reliable protocol for the recovery of " $S$ milleri group" isolates from defined sites in the oral cavity; (ii) to develop a simple, rapid, and cheap battery of biochemical and serological tests for the presumptive identification of " $S$ milleri group" isolates from the mouth and other sources that would be capable of recognising the various haemolytic types, serological groups, and biotypes known to exist within this taxon; and (iii) to establish a culture collection of group $\mathrm{F}$ streptococcal strains from a range of sites, and of different haemolytic and biotypes.

\section{Methods}

Dental plaque was recovered on sterile McCall's curettes from two non-inflamed sites in the mouths of 12 healthy adult volunteers (five men, seven women), lingual to a lower first permanent molar tooth and distolabial to an upper canine tooth. The plaque was dispersed into $1.0 \mathrm{ml}$ reduced transport fluid (RTF). ${ }^{24}$ Samples were transported to the laboratory within one hour and dispersed in RTF by vortexing before serial dilution in RTF. Dilu- 
Table 1 List of reference and clinical strains included in this study

Reference strains:

1 "S milleri group" reference strains:

$\begin{array}{ll}\text { Number } & \text { Species } \\ \text { NCTC } 10707 & \text { Lancefield group F streptococcus } \\ \text { NCTC } 10714 & \text { Lancefield group F streptococcus } \\ \text { NCTC } 5389 & \text { Lancefield group F streptococcus } \\ \text { NCTC } 8037 & \text { S anginosus (Lancefield group F) } \\ \text { NCTC } 11065 & \text { "S milleri", } \\ \text { NCTC } 11063 & \text { "S milleri" } \\ \text { NCTC } 11169 & \text { "S milleri", } \\ \text { NCTC } 10708 & \text { "S milleri" }\end{array}$

Other streptococcal reference strains:

$\begin{array}{ll}\text { NCTC } 7864 & S \text { sanguis } \\ \text { NCTC } 8606 & S \text { salivarius } \\ \text { NCTC } 10449 & S \text { mutans } \\ \text { NCTC } 10712 & S \text { mitior }\end{array}$

Clinical strains:

\begin{tabular}{lll} 
& Diagnosis & Source \\
CBB1 & "S milleri" (Lancefield group F) & High vaginal swab \\
CBB2 & "S milleri" (Lancefield group F) & High vaginal swab \\
CBB3 & Group F streptococcus & Pilonidal sinus \\
CBB5 & Group F streptococcus & Infected dental cyst \\
CBB6 & Group F streptococcus & Neonatal skin swab \\
CBB8 & Group F streptococcus & Throat swab \\
CBB9 & "S milleri" (Lancefield group F) & Arm abscess \\
CBB10 & Group F streptococcus & Denture swab \\
H957 & Group F streptococcus & Chin abscess \\
\hline
\end{tabular}

tions $\left(0 \cdot 2 \mathrm{ml}\right.$ of $\left.10^{-3}, 10^{-4}, 10^{-5}\right)$ were spread on to the surface of a single selective medium (MC agar: a sulphonomide-containing medium similar in composition to mitis salivarius agar described by Carlsson in 1967,,$^{25}$ and modified in the current study by the replacement of sulphadimetine with sulphadimidine) with sterile glass spreaders, and incubated in $10 \%$ $\mathrm{CO}_{2}, 90 \% \mathrm{H}_{2}$, in anaerobic jars without catalysts for 48 hours at $37^{\circ} \mathrm{C}$. Colonies morphologically resembling " $S$ milleri" were selected and subcultured on blood agar. One or more further subcultures was sometimes required to obtain pure cultures which were subjected to identification procedures.

Table 1 shows additional clinical " $S$ milleri group" isolates, obtained from the Clinical Bacteriology Laboratory, University of Edinburgh, and reference strains included in this study.

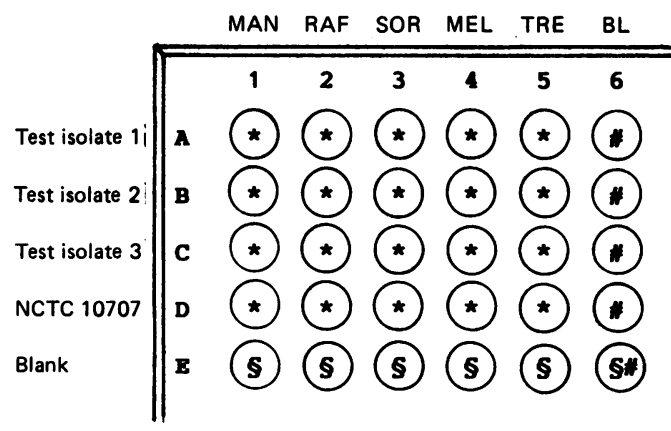

Schematic representation of RCUT test prepared for identification of three test isolates. Numbers 1-6 and letters $A-E$ represent row numbers of a microtitre plate. $M A N=$ Mannitol $\quad M E L=$ Melibiose $R A F=$ Raffinose $\quad T R E=$ Trehalose SOR $=$ Sorbitol $\quad B L=$ Blank

Wells marked * received both indicated organism and

sugar.

Wells marked \# received organism, but no sugar.

Wells marked \$ received sugar, but no organism.

The well marked $\$$ received neither sugar nor organism.
BIOCHEMICAL IDENTIFICATION

Carbohydrate fermentation tests

Fermentation of mannitol, raffinose, sorbitol, melibiose and trehalose was by a method modified from the rapid carbohydrate utilisation test (RCUT) of Young. ${ }^{26}$ The RCUT was conveniently performed in the wells of microtitre plates as follows:

(1) $100 \mu \mathrm{l}$ of buffered salt solution containing neutral red indicator (BSS) ${ }^{26}$ were added to six wells in a microtitre plate, and $250 \mu \mathrm{l}$ to a small, sterile glass tube for each organism to be examined. Control wells were also set up as indicated in the figure.

(2) $25 \mu \mathrm{l}$ of $10 \%(\mathrm{w} / \mathrm{v})$ aqueous solutions of mannitol, raffinose, sorbitol, melibiose and trehalose were added, respectively, to one of five wells for each test organism, and to appropriate control wells as indicated in the figure.

(3) Growth from a fresh, overnight blood-agar culture was harvested with a cotton-tipped swab, and used to make a dense suspension in the $250 \mu \mathrm{l}$ BSS contained in the test tube. Volumes $(25 \mu \mathrm{l})$ of this suspension were added to test wells of the microtitre plate, and to appropriate control wells (figure).

(4) Plates were incubated at $37^{\circ} \mathrm{C}$ by floating in a waterbath, and a definitive reading (colour change of red to yellow) was made after four hours.

Each day, a fresh culture of Lancefield group F streptococcus (NCTC 10707) was used as a positive "S milleri" control.

Voges-Proskauer (VP) reaction

This was achieved by the rapid method of Bucher and von Graevenitz, ${ }^{27}$ using fresh culture of Lancefield group F streptococcus (NCTC 10707) as a positive control.

\section{Arginine hydrolysis}

This was carried out according to the method of Niven $e t a^{28}$ as described by Cowan and Steel, ${ }^{29}$ with a stock strain of Enterococcus faecalis as a positive control.

\section{Aesculin hydrolysis}

This was carried out using two methods: (i) the method of Cowan and Steel ${ }^{29}$; and (ii) the method of Brown et al..$^{30}$ A stock strain of $E$ faecalis was the positive control in each test.

\section{SEROLOGICAL IDENTIFICATION}

Serological identification was performed by geldiffusion in Ouchterlony gels. ${ }^{31}$

\section{Antigenic extracts}

$C$ antigen was extracted from the cells contained in a heavy sweep from a fresh blood-agar culture by the method of El Kholy et al. ${ }^{3233}$ Each day fresh cultures of laboratory stock strains of Lancefield group A, C, and G streptococci, and Lancefield group $F$ streptococcus (NCTC 10707) were used as controls.

\section{Antisera}

Antiserum was raised in a Dutch rabbit by the method of Poxton. ${ }^{34}$ The vaccine was $10^{9}$ bacteria which had been irradiated with a lethal dose of ultraviolet light. Antiserum was raised 
Table 2 Biochemical characterisation of some streptococcal reference strains

\begin{tabular}{|c|c|c|c|c|c|c|c|c|}
\hline Strain & $M A N^{I}$ & $R A F^{\prime}$ & $S O R^{\prime}$ & $M E L^{\prime}$ & $T R E^{\prime}$ & $A R G^{2}$ & $A E S C^{2}$ & $V P^{3}$ \\
\hline$S$ sanguis (NCTC 7864) & - & + & - & + & + & - & - & - \\
\hline$S$ salivarius (NCTC 8606) & - & + & - & + & + & - & + & - \\
\hline$S$ mutans (NCTC 10449) & + & + & + & + & + & - & + & + \\
\hline$S$ mitior (NCTC 10712) & - & + & - & + & + & - & - & - \\
\hline $\begin{array}{l}\text { Lancefield group } \\
\text { F streptococcus (NCTC 10707) }\end{array}$ & - & - & - & - & + & + & + & + \\
\hline $\begin{array}{l}\text { Lancefield group } \\
\text { F streptococcus (NCTC 10714) }\end{array}$ & - & - & - & - & + & + & - & + \\
\hline $\begin{array}{l}\text { Lancefield group } \\
\text { F streptococcus (NCTC 5389) }\end{array}$ & - & - & - & - & + & + & + & + \\
\hline$S$ angiosus (NCTC 8037) & - & - & - & - & + & + & + & + \\
\hline "S milleri" (NCTC 11065) & - & - & - & - & + & + & + & + \\
\hline "S milleri" (NCTC 11063) & - & - & - & - & + & + & - & + \\
\hline “S milleri" (NCTC 10708) & - & - & - & - & + & + & + & + \\
\hline "S milleri" (NCTC 11169) & - & - & - & - & + & + & + & + \\
\hline
\end{tabular}

1 Rapid carbohydrate utilisation test:

MAN = Mannitol; RAF = Raffinose; SOR = Sorbitol; MEL = Melibiose $;$ TRE $=$ Trehalose.

2 Hydrolysis reactions:

3 Production of acetoin from glucose:

3 Production of acetoin from glucos

$t=$ Positive test reaction.
P

$+=$ Negative test reaction.

against Lancefield group F streptococcus (NCTC 10707). Commercial antisera (groups A, C, G, and F) were obtained from Wellcome.

\section{Results}

A collection of reference strains was first examined by the short series of biochemical tests to establish its ability to differentiate "S milleri group" strains from single strains of $S$ sanguis (NCTC 7864), $S$ salivarius (NCTC $8606), S$ mutans (NCTC 10449), and $S$ mitior (NCTC 10712), and to establish the reproducibility of results. Table 2 shows the results of tests, which were repeated on three consecutive days and gave entirely reproducible results. RCUT tests were clearly read after four hours, and Voges-Proskauer tests after five hours. Determination of arginine hydrolysis required incubation for 24 hours, while aesculin hydrolysis often required incubation for 48 hours before a definitive reading could be made.

The eight " $S$ milleri group" reference strains tested represented a relatively homogeneous collection of strains, fermenting only trehalose, giving a positive Voges-Proskauer reaction,

Table 3 Summary of characteristics of 127 "S milleri group" isolates recovered from mouths of 10 volunteers

\begin{tabular}{|c|c|c|c|}
\hline & & \multicolumn{2}{|c|}{$\begin{array}{l}\text { Number }(\%) \text { of isolates } \\
\text { positive }\end{array}$} \\
\hline $\begin{array}{l}\text { Biochemical tests } \\
\text { Mannitol } \\
\text { Raffinose } \\
\text { Sorbitol } \\
\text { Melibiose } \\
\text { Trehalose } \\
\text { Arginine } \\
\text { Aesculin } \\
\text { VP }\end{array}$ & & $\begin{array}{r}6 \\
6 \\
6 \\
2 \\
119 \\
118 \\
103 \\
119\end{array}$ & $\begin{array}{l}(4 \cdot 7) \\
(4 \cdot 7) \\
(4 \cdot 7) \\
(1 \cdot 6) \\
(93 \cdot 7) \\
(92 \cdot 9) \\
(81 \cdot 1) \\
(93 \cdot 7)\end{array}$ \\
\hline Serological group & $\begin{array}{l}\text { A } \\
\mathbf{C} \\
\mathbf{F} \\
\mathbf{G} \\
\text { No group }\end{array}$ & $\begin{array}{r}0 \\
1 \\
46 \\
7 \\
73\end{array}$ & $\begin{array}{l}(0) \\
(0 \cdot 8) \\
(36 \cdot 2) \\
(5 \cdot 5) \\
(57 \cdot 5)\end{array}$ \\
\hline Haemolysis & $\begin{array}{l}\alpha \\
\beta \\
\text { None }\end{array}$ & $\begin{array}{r}33 \\
5 \\
89\end{array}$ & $\begin{array}{r}(26 \cdot 0) \\
(3 \cdot 9) \\
(70 \cdot 1)\end{array}$ \\
\hline
\end{tabular}

VP = Voges-Proskauer reaction hydrolysing arginine, and in all but two cases hydrolysing aesculin.

Although differentiating " $S$ milleri group" strains from the single representatives of $S$ sanguis, $S$ salivarius, $S$ mutans, and $S$ mitior, differentiation among the other strains was not entirely clear. The single $S$ mutans strain, however, was clearly identified by its wide carbohydrate utilisation pattern, positive Voges-Proskauer reaction, aesculin hydrolysis, and its failure to hydrolyse arginine.

Serological tests correctly identified Lancefield group F streptococci (NCTC 10707, NCTC 5389, NCTC 10714), and $S$ anginosus (NCTC 8037) as group F strains. None of the other strains reacted with the range of antisera used in this study. Serological results were clearly read within five hours.

A simple sampling procedure, in combination with a single selective medium, permitted the isolation of 177 streptococcal isolates which were examined further. Within this collection of isolates 127 " $S$ milleri group" isolates were identified by the short series of tests from the mouths of 10 of the 12 subjects sampled.

The results of biochemical and serological tests for 127 " $S$ milleri group" isolates, repeated in duplicate, are shown in table 3 . Most isolates fermented trehalose, hydrolysed arginine and aesculin, and gave a positive Voges-Proskauer reaction. A few, however, utilised mannitol, raffinose, sorbitol or melibiose. Most (70.1\%) isolates were nonhaemolytic, and of the five (3.9\%) $\beta$-haemolytic isolates, three were Lancefield group $\mathrm{G}$ and two were ungroupable within the range of antisera used. In total, $54(42.5 \%)$ ) of the 127 oral " $S$ milleri group" isolates were serologically groupable, most $(n=46)$ of these strains belonging to Lancefield group F. In all instances the results obtained with antiserum raised against Lancefield group F streptococcus (NCTC 10707) agreed with the commercial group $F$ antiserum. In addition to the $\mathbf{4 6}$ oral group F strains obtained in the current study, nine clinical group F strains and four NCTC reference strains (table 1) contributed to a collection of 59 Lancefield group F streptococcal strains. The range of biochemical profiles 
Table 4 Biochemical characterisation of 59 group F streptococci, including oral, clinical, and NCTC isolates

\begin{tabular}{|c|c|c|c|c|c|c|c|c|c|}
\hline \multicolumn{2}{|c|}{$\begin{array}{l}\text { Number of isolates with } \\
\text { given biochemical profile }\end{array}$} & $M A N^{\prime}$ & $R A F^{\prime}$ & $S O R^{\prime}$ & $M E L^{\prime}$ & $T R E^{\prime}$ & $A R G^{2}$ & $A E S C^{2}$ & $V P^{3}$ \\
\hline & 44 & - & - & - & - & + & + & + & + \\
\hline & 4 & - & - & - & - & + & + & + & - \\
\hline & 2 & - & - & - & - & + & + & - & + \\
\hline & 2 & - & + & - & + & - & + & + & + \\
\hline & 2 & - & + & - & - & + & - & + & + \\
\hline & 1 & - & - & - & - & + & - & - & + \\
\hline \multirow{4}{*}{$\vdots$} & 1 & + & - & + & - & + & + & + & + \\
\hline & 1 & - & - & - & - & + & + & - & - \\
\hline & 1 & - & - & - & - & + & - & + & + \\
\hline & 1 & - & - & - & + & - & - & - & + \\
\hline Total: & $\begin{array}{c}59 \\
(100)\end{array}$ & $\stackrel{1}{(1 \cdot 7)}$ & $\begin{array}{c}4 \\
(6 \cdot 8)\end{array}$ & $\stackrel{1}{(1 \cdot 7)}$ & $\begin{array}{l}3 \\
(5 \cdot 1)\end{array}$ & $\begin{array}{c}56 \\
(94.9)\end{array}$ & $\begin{array}{c}54 \\
(91 \cdot 5)\end{array}$ & $\begin{array}{c}54 \\
(91 \cdot 5)\end{array}$ & $\begin{array}{c}54 \\
(91.5)\end{array}$ \\
\hline
\end{tabular}

1 Rapid carbohydrate utilisation test:

MAN = Mannitol; RAF = Raffinose; SOR = Sorbitol; MEL = Melibiose; TRE $=$ Trehalose.

2 Hydrolysis reactions:

ARG = Arginine; AESC = Aesculin

3 Production of acetoin from glucose:

VP = Voges-Proskauer reaction.

$+=$ Positive test reaction.

$+=$ Positive test reaction.
$-=$ Negative test reaction.

encountered in this culture collection is shown in table 4 . Thirty eight $(64.4 \%)$ were nonhaemolytic, $16(27 \cdot 1 \%) \alpha$-haemolytic, and five $(8.5 \%) \beta$-haemolytic. Most $(74.6 \%)$ formed a biochemically homogeneous group, but strains were found which displayed differing fermentation profiles. No differentiation could be made between Lancefield group F and non-Lancefield group $\mathrm{F}$ " $S$ milleri group" isolates on the basis of the biochemical tests used in this study.

\section{Discussion}

In the first part of this study a series of simple biochemical and serological tests were developed for the presumptive identification of "S milleri group" reference strains. Differentiation of "milleri group" streptococci from a small collection of oral streptococcal reference strains was readily achieved, though differentiation among other species tested was not always clear. Although beyond the scope of the current study, it is suggested that a fuller evaluation of this system with a broad range of oral streptococci of known identity would be required to modify the range of tests for the presumptive identification of a greater number of species.

Tests for the production of hyaluronidase, and the ability to degrade synthetic fluorogenic substrates described recently by Whiley et $a l,{ }^{23}$ were not included in this study, and the differentiation of strains within the " $S$ milleri group" corresponding to $S$ anginosus, $S$ intermedius, and $S$ constellatus was consequently not possible.

The single selective medium used in this study proved effective for the recovery of " $S$ milleri group" isolates from the mouth and confirmed the association of this group with the human gingival crevice. ${ }^{435}$

Oral " $S$ milleri group" isolates represented a relatively homogeneous group on the basis of the tests undertaken, though a small number of isolates $(9.4 \%)$ was encountered which were able to ferment mannitol, raffinose, sorbitol, or melibiose. This proportion of oral " $S$ milleri group" isolates with wide sugar fermentation profiles was comparable with the findings of Ball and Parker. ${ }^{20}$
In common with previous studies on " $S$ milleri group" isolates from the mouth" 20233536 most isolates found in our study were nonhaemolytic and possessed no recognisable Lancefield grouping antigen, properties typical of the $S$ intermedius taxon described by Whiley et $a l^{23}$ A high proportion of oral " $S$ milleri group" isolates, however, were serologically groupable, and of these, Lancefield group F was by far the commonest, which agrees with the findings of other workers. ${ }^{353}$ All of the oral group F isolates found were either $\alpha$ or nonhaemolytic, suggesting that they would most likely belong to the $S$ anginosus taxon. ${ }^{23}$

Further tests would be required to confirm these intuitive associations because it is recognised that haemolytic reactions, Lancefield group status, and behaviour in traditional biochemical tests are of little practical value in identifying the three taxa shown within the " $S$ milleri group". ${ }^{23}$ The results of this study supported this observation because a collection of Lancefield group $F$ streptococci from a range of sources was indistinguishable from a collection of oral "S milleri group" isolates on the basis of the tests used.

These observations notwithstanding, the system of tests described in the current report were regarded as satisfactory for the rapid presumptive identification of "S milleri group" isolates from a range of sources. Inoculation of tests from a pure plate culture, in addition to short incubation times in non-nutrient medium, reduced to a minimum the potential problems of contamination, while the small volumes of reagents and the use of non-sterile microtitre plates kept the cost of media and consumables low.

JMW acknowledges receipt of University of Edinburgh Bonnar Research Fellowship E606/627.

1 Unsworth PF, Fraser CAM, Hallas G, Widdowson J. A method of serotyping the hyaluronidase produced by some strains of Streptococcus milleri and the pathogenesis in man of abscesses due to this organism. J Med Microbiol 1980;13:vi-vii.

2 Ruoff KL, Fishman JA, Calderwood SB, Kunz LJ. Distribution and incidence of viridans streptococcal species in routine clinical specimens. Am J Clin Pathol 1983;80: 854-8. 
3 Poole PM, Wilson G. Occurrence and cultural features of Streptococcus milleri in various body sites.J Clin Pathol Streptococcus

4 Mejàre B, Edwardsson S. Streptococcus milleri (Guthof); an indigenous organism of the human oral cavity. Arch Oral Biol 1975;20:757-62.

5 Hardie JM, Thomson PL, South RJ, et al. A longitudinal study on dental plaque and the development of dental caries-interim results after two years. J Dent Res 1977 56(Special issue C): $\mathrm{C} 90-\mathrm{C} 8$.

6 Tresadern JC, Farrand RJ, Irving MH. Streptococcus milleri and surgical sepsis. Ann R Coll Surg Eng 1983; 65:78-9.

7 Moore-Gillon JC, Eykyn SJ, Phillips I. Microbiology of pyogenic liver abscess. Br Med J 1981;283:819-20.

8 Waitkins SA, Ratcliffe JG, Roberts C. Streptococcus milleri found in pulmonary empyemas and abscesses. $J$ Clin found in pulmonary em

9 De Louvois J. Bacteriological examination of pus from abscesses of the central nervous system. J Clin Patho 1980;33:66-71

10 Lewis MAO, MacFarlane TW, McGowan DA Quantitative bacteriology of acute dentoalveolar abscesses. J Med Microbiol 1986;21:101-4.

11 Skerman VBD, McGowan V, Sneath PHA. Approved lists of bacterial names. Int $J$ Syst Bacteriol 1980;30:225-420.

12 Andrewes FW, Horder TJ. A study of the streptococci pathogenic for man. III. Proposed classification of streptococci based upon all characters and including Gordon's tococci based upon all charact 1906 ;ii:711-13.

13 Long PH, Bliss EA. Studies on minute haemolytic streptococci; isolation and cultural characteristics of minute

14 Mirick GS, Thomas L, Curnen EC, Horsfall FL. Studies on a non-hemolytic streptococcus isolated from the respiratory tract of human beings. I. Biological characteristics of Streptococcus MG. J Exp Med 1944;80:391-406.

15 Guthof $O$. Ueber pathogene "vergrünende Streptokokken": Streptokokken-Befunde bei dentogenen Abszessen und infiltraten im Bereich der Mundhöhle. Zentralbl Bacterio Parasitenkd Infectionskr Hyg.1. Abteilung Originale 1956; 166:533-64

16 Colman G, Williams REO. Taxonomy of some viridans streptococci. In: Wannamaker LW, Matsen JM, eds. Streptococci and streptococcal disease. Recognition, understrepting and management. New York: Academic Press, standing and

17 Holdeman LV, Moore WEC. New genus, Coprococcus, twelve new species, and amended descriptions of four previously described species of bacteria from human feces. Int J Syst Bacteriol 1974;24:260-77.

18 Facklam RR. The major differences in the American and British Streptococcus taxonomy schemes with special reference to Streptococcus milleri. Eur J Clin Microbio 1984;3:91-3.

19 Facklam RR. Physiological differentiation of viridans streptococci. J Clin Microbiol 1977;5:184-201.

20 Ball LC, Parker MT. The cultural and biochemical charac- ters of Streptococcus milleri strains isolated from human sources. J Hyg (Camb) 1979;82:63-78.

21 Coykendall AL, Wesbecher PM, Gustafson KB. "Streptococcus milleri", Streptococcus constellatus, and Streptococcus intermedius are later synonyms of Streptococcus anginosus. Int $J$ Syst Bacteriol 1987;37:222-8.

22 Whiley RA, Hardie JM. DNA-DNA hybridisation studies and phenotypic characteristics of strains within the "Streptococcus milleri group". J Gen Microbiol 1989;135: 2623-33.

23 Whiley RA, Fraser H, Hardie JM, Beighton D. Phenotypic differentiation of Streptococcus intermedius, Streptococcus constellatus, and Streptococcus anginosus strains within the "Streptococcus milleri group". J Clin within the "Streptococcus

24 Syed SA, Loesche WJ. Survival of human dental plaque flor in various transport media. Appl Microbiol 1972;24: in various

25 Carlsson J. A medium for isolation of Streptococcus mutans. Arch Oral Biol 1967;12:1657-8.

26 Young H, Paterson IC, McDonald DR. Rapid carbohydrate utilisation test for the identification of Neisseria gonorrhoea. Br J Vener Dis 1976;52:172-5.

27 Bucher C, von Graevenitz A. Differentiation in throat cultures of group C and G streptococci from Streptococcus milleri with identical antigens. Eur J Clin Microbio 1984;3:44-5.

28 Niven CF Jr, Smiley KL, Sherman JM. The hydrolysis of arginine by streptococci. J Bacteriol 1942;43:651-60

29 Cowan ST, Steel KJ. Manual for the identification of medical bacteria. 1 st ed. Cambridge: Cambridge University Press, 1965.

30 Brown R, Collee JG, Poxton IR, Fraser AG. Bacteroides, Fusobacterium and related organisms: anaerobic cocci: identification of anaerobes. In: Collee JG, Duguid JP, Fraser AG, Marmion BP, eds. Mackie $\mathcal{E}$ McCartney. Practical medical microbiology, 13th ed. Edinburgh: Churchill Livingstone, 1989:562.

31 Freimer EH. Studies on L forms and protoplasts of group A streptococci. II. Chemical and immunological properties of the cell membrane. J Exp Med 1963;117:377-99.

32 El Kholy A, Wannamaker LW, Krause RM. Simplified extraction procedure for serological grouping of betahaemolytic streptococci. Appl Microbiol 1974;28:836-9.

33 El Kholy A, Facklam R, Sabri G, Rotta J. Serological identification of group A streptococci from throat scrapings before culture. J Clin Microbiol 1978;8:725-8.

34 Poxton IR. Serological identification of Bacteroides species by enzyme-linked immunosorbent assay. J Clin Pathol by enzyme-link

35 Yakushiji T, Katsuki M, Yoshimitsu A, Mizuno J, Inoue M Isolation and physiological characterisation of Streptococcus milleri strains from human dental plaque. Microbios 1988;55:161-71.

36 Lütticken $R$, Wendorff $U$, Lütticken $D$, Johnson EA Wannamaker LW. Studies on streptococci resembling Streptococcus milleri and on an associated surface-protein antigen. J Med Microbiol 1978;11:419-30. 